\title{
Factors affecting medication adherence in
}

\section{community-managed patients with hypertension based on the principal component analysis: evidence from Xinjiang, China}

This article was published in the following Dove Press journal:

Patient Preference and Adherence

\section{Yuji Zhang* \\ Xiaoju Li* \\ Lu Mao \\ Mei Zhang \\ Ke Li \\ Yinxia Zheng \\ Wangfei Cui \\ Hongpo Yin \\ Yanli He \\ Mingxia Jing}

Department of Public Health, Shihezi University School of Medicine, Shihezi, Xinjiang, China

*These authors contributed equally to this work
Correspondence: Mingxia Jing Department of Public Health, Shihezi University School of Medicine, $280 \mathrm{~N}$ 4th Road, Shihezi, Xinjiang 832002, China

Tel +86 I829937 7776

Email jingmingxia |26@|26.com
Purpose: The analysis of factors affecting the nonadherence to antihypertensive medications is important in the control of blood pressure among patients with hypertension. The purpose of this study was to assess the relationship between factors and medication adherence in Xinjiang community-managed patients with hypertension based on the principal component analysis.

Patients and methods: A total of 1,916 community-managed patients with hypertension, selected randomly through a multi-stage sampling, participated in the survey. Self-designed questionnaires were used to classify the participants as either adherent or nonadherent to their medication regimen. A principal component analysis was used in order to eliminate the correlation between factors. Factors related to nonadherence were analyzed by using a $\chi^{2}$-test and a binary logistic regression model.

Results: This study extracted nine common factors, with a cumulative variance contribution rate of $63.6 \%$. Further analysis revealed that the following variables were significantly related to nonadherence: severity of disease, community management, diabetes, and taking traditional medications.

Conclusion: Community management plays an important role in improving the patients' medication-taking behavior. Regular medication regimen instruction and better community management services through community-level have the potential to reduce nonadherence. Mild hypertensive patients should be monitored by community health care providers.

Keywords: hypertension, medication adherence, factors, principal component analysis, community management, China

\section{Introduction}

Hypertension is one of the major public health issues around the world and is among the major modifiable risk factors of cardiovascular diseases. ${ }^{1,2}$ The World Health Organization (WHO) reported that hypertension is estimated to have caused 9.4 million deaths and $7 \%$ of the disease burden in 2010 , and the situation is still deteriorating. ${ }^{3}$ In China, the prevalence of hypertension is $32.5 \%$. About one-third of Chinese adults need antihypertensive treatment, but only $46.4 \%$ of them are being treated with antihypertensive medications, resulting in an overall control rate of $4.2 \%$. ${ }^{4}$ Nonadherence to antihypertensive medication is the main reason for the ineffective control of blood pressure. One study had shown that patients' adherence to their medication regimen reduces the risk of myocardial infarction by $20 \%-25 \%$, cardiac failure by $>50 \%$, and stroke by $35 \%-40 \%{ }^{5}$ Nonadherence to medication regimens is common among 
patients with hypertension worldwide, especially in China, with nonadherence rate ranged from $40.3 \%$ to $78.7 \%{ }^{6-10}$ Hence, the factors associated with adherence to antihypertensive medications have been a topic of interest.

Factors that affect adherence to antihypertensive medications are complex. The WHO classified those multidimensional factors into patient-, social/economic-, condition-, therapy-, and health care team-related factors. ${ }^{11}$ Community management is the main factor that influences the effects of treatment and control of blood pressure in patients with hypertension. Fikri-Benbrahim et al conducted a survey in Spanish and found that medication adherence in patients with hypertension under the management of a community pharmacist is 4.07 times higher than those without management. ${ }^{12}$ A study conducted in the USA showed that medication adherence increased by $36 \%$ through regular follow-ups, individualized education on medication by community pharmacists, and the use of blister packs in dispensing medications. ${ }^{13}$ Two systematic reviews reported that medication management, educational interventions directed to the patients, and more frequent follow-up appointments or contacts were the most frequently used community management methods in many countries, effectively increasing the medication adherence of patients. ${ }^{14,15}$ In 2009, China launched new health care reforms, which include strategies that are closely linked with chronic disease control, including management of hypertension. Patients with hypertension aged $\geq 35$ years were provided free management services by the local primary health care workers, including health records, free blood pressure measurement, regular follow-ups every 3 months, and health education. ${ }^{16,17}$

Many studies were conducted to investigate the factors associated with medication adherence in community-managed patients with hypertension. ${ }^{8,18-25}$ Wang et al analyzed seven factors, including age, gender, and number of comorbidities, affecting the medication adherence among Chinese community-managed elderly patients with hypertension by using a multivariate linear regression model. ${ }^{20}$ The same model was also used by Ma to analyze 13 factors, including age, gender, and medications used, associated with antihypertensive medication adherence in patients living in the rural areas of Shanxi, China. ${ }^{8}$ Moreover, Bishopric et al analyzed 29 factors affecting the medication adherence of patients with hypertension living in a rural Vietnamese community by using a multiple logistic regression model. ${ }^{19}$ Most studies used a regression model to analyze the multidimensional factors that affect the patients' adherence to antihypertensive medications. ${ }^{26-31}$ Although these factors maybe correlated, it was difficult to propose a strategy to improve the measures for medication adherence using a unidimensional factor. On the other hand, a regression model could not solve the colinearity in complex factors. Thus, this study reduced dimensions to solve colinearity in multidimensional factors of medication adherence by using a principal component analysis method, which was convenient for policy makers to make future interventions.

Xinjiang is located in the northwestern region of China. In 2015, the per capita gross domestic product of Xinjiang was 40,036 yuan, and the number of general practitioners per 10,000 permanent populations were 1.25 ; it has an underdeveloped economy and has areas with relatively scanty health resources. ${ }^{32,33}$ The prevalence of hypertension in Xinjiang is $33.34 \%$, which was higher than the national prevalence rate. However, the control rate is only $10.8 \%{ }^{34}$ Prior studies reported that the prevalence of medication adherence among patients with hypertension in Xinjiang ranged from $34.0 \%$ to $53.5 \%$, which was also higher than the national prevalence rate. ${ }^{10,35-40}$ The patients with hypertension in Xinjiang had poor medication adherence and blood pressure control. Thus, this study aimed to assess the relationship between factors and medication adherence in Xinjiang community-managed patients with hypertension using the principal component analysis, with a certain reference to other areas with underdeveloped economies and scanty health sources.

\section{Patients and methods}

\section{Sampling and settings}

We conducted a cross-sectional survey by using a selfdesigned questionnaire at three areas in Xinjiang, China, between April and August 2016. A total of 1,916 patients with hypertension participated in this study. Using a multi-stage sampling method based on the economic status and population size in Xinjiang, nine communities of the three areas were selected as samples. The following were the inclusion criteria of this study: individuals who 1) were diagnosed with hypertension by clinical doctors, 2) were managed by a community, 3 ) had a systolic blood pressure $\geq 140 \mathrm{mmHg}$ and/or a diastolic blood pressure $\geq 90 \mathrm{mmHg}$, and 4) were taking at least one antihypertensive medication during the survey period. On the other hand, the exclusion criteria were as follows: those who 1) had communication difficulties such as visual impairment and poor hearing, 2) exhibited severe cognitive impairment or diagnosed with dementia and mental disorder, 3) were too sick to participate in this study, and 4) were uncooperative. A pilot study was conducted on one of the sampled community, which was composed of 
159 patients with hypertension who were not included in the final study sample.

The sample size was calculated based on the number of participants required to maintain a statistical power for the statistical tests used in data analysis. Since there was no available literature showing the prevalence of adherence among the Xinjiang community in general, the following variables were used: an expected prevalence rate of $76 \%,{ }^{41}$ a two-sided, 0.05 significance level test with a $90 \%$ statistical power, and a minimum of 127 participants.

\section{Questionnaire and definition of variables}

A self-designed questionnaire was used as a data collection tool, which was designed similar to that used in the extensive literature review of similar studies. ${ }^{38,42,43}$ The questionnaire included: 1) patient's demographics such as age, sex, marital status, education, insurance, annual household income, and number of family members; 2) clinical characteristics such as health status, comorbidities, sickness status, and blood pressure control status; 3) patient's medication adherence; and 4) health services used such as outpatient visits, hospitalization visits, and emergency visits. The data were collected through a face-to-face interview, which lasted for an average of 15-20 minutes.

This study used the following self-report questions to measure the patient's medication adherence: 1) Can you take your antihypertensive medication everyday based on the frequency prescribed by doctors? 2) Can you take your antihypertensive medication everyday based on the timing prescribed by doctors? 3) Can you take your antihypertensive medication everyday based on the required dose prescribed by doctors? and 4) Do you continuously take your antihypertensive medication? The 4-scale answers of the first three questions include: 1) never complete, 2) sometimes complete, 3) usually complete, and 4) always complete. The patients were asked to select the following options to answer the last question: 1) discontinued the medication, 2) took the medications intermittently, 3) took the medications continuously but below the prescribed dose, and 4) took the medications continuously without interruption. The participants who chose either the third or the fourth options as answers to all four questions were identified as adherent; those who did not were considered as nonadherent. ${ }^{44,45}$ The standardized Cronbach's $\alpha$, a measure of reliability, was a total of 0.804 .

In addition, blood pressure control is considered as a binary variable; thus, patients with a systolic blood pressure $<140 \mathrm{mmHg}$ and/or a diastolic blood pressure $<90 \mathrm{mmHg}$ are regarded as having control over their blood. ${ }^{42,43}$ Regular clinical check was a binary variable, patients who were considered having regular clinical check should have at least once clinical check within 3 months, otherwise they were considered to have no regular clinical check. Regular blood pressure check was a dichotomous variable, patients with regular blood pressure check should measure their blood pressure at least once within a week, if not, they were considered to have no regular blood pressure check. Complication variable was divided into two categories based on whether patients had hypertension-related complications or not. Number of comorbidities was divided into three categories: having no comorbidity, having one or two comorbidities, and having more than three comorbidities. In this study, comorbidity was referred to other chronic diseases except hypertension. All patients were categorized as insured or uninsured for outpatient medical reimbursement policy. Duration was divided into three categories based on the time that patients were diagnosed with hypertension. Self-reported severity of hypertension was divided into four categories based on the patients' severity of their disease.

\section{Data analysis}

Statistical analyses were performed using the SPSS version 24.0. Frequencies and percentages were calculated for categorical variables. The categorical variables were tested using a univariate chi-square test. This study used a principal component analysis to transform some of the factors into aggregative indicators in order to eliminate the correlation between factors. A binary logistic regression analysis was used to evaluate the odds ratios of factors that showed a statistically significant association with the medication adherence in the univariate analysis. $P$-value $<0.05$ was considered statistically significant.

\section{Ethics statement}

This study was approved by the Ethics Committee of the Shihezi University. The study was funded and permitted by the National Natural Science Foundation of China (project identification code: 71363047). The participants were assured that their answers in this study would not impact their subsequent benefits. Their personal information such as name, address, and identification number were collected to be used in the later follow-up studies, and all data are kept strictly confidential and secured. The data gathered are only used in this study. Investigators read and explained the informed consent, and all participants gave written informed consent (signed or fingerprinted if illiterate) before the questionnaire began. 


\section{Results}

\section{Sample characteristics}

The demographic characteristics of the respondents are shown in Table 1; a total of 2,191 patients with hypertension participated in this study, with an effective response rate of $87.4 \%$. However, the number of samples selected in this study was only a total of 1,916 . Females accounted for $1,154(60.2 \%)$ of the total samples. The average age of the total samples was $72.21 \pm 7.707$ years (from 38 to 97 years). Most of them were living with more than one family member
(87.2\%) and some were married (79.3\%). Most of them were retired $(92.7 \%)$ and some of them availed the outpatient medical reimbursement policy (29.6\%). Just one-third of the patients were either illiterate (37.9\%) or only had attained primary education (33.0\%), and one-tenth of them had attained high school education or above (10.5\%). Using a bivariate analysis, this study found that age, residence, educational level, annual household income, and outpatient medical reimbursement were statistically associated with nonadherence $(P<0.05)$. Patients living in rural areas and those with no

Table I Adherence level based on sociodemographic characteristics

\begin{tabular}{|c|c|c|c|c|c|c|c|c|}
\hline \multirow[t]{2}{*}{ Demographic characteristics } & \multicolumn{2}{|c|}{$\begin{array}{l}\text { Total } \\
(n=1,9 \mid 6)\end{array}$} & \multicolumn{2}{|c|}{$\begin{array}{l}\text { Adherence } \\
(n=1,629)\end{array}$} & \multicolumn{2}{|c|}{$\begin{array}{l}\text { Nonadherence } \\
(\mathrm{n}=\mathbf{2 8 7})\end{array}$} & \multirow[t]{2}{*}{$\chi^{2}$} & \multirow[t]{2}{*}{$P$-value } \\
\hline & $\mathbf{n}$ & $\%$ & $\mathbf{n}$ & $\%$ & $\mathbf{n}$ & $\%$ & & \\
\hline Age (years) & & & & & & & 12.564 & $0.014^{\mathrm{a}}$ \\
\hline $35-64$ & 249 & 13.0 & 203 & 81.5 & 46 & 18.5 & & \\
\hline $65-69$ & 352 & 18.4 & 287 & 81.5 & 65 & 18.5 & & \\
\hline $70-74$ & 514 & 26.8 & 458 & 89.1 & 56 & 10.9 & & \\
\hline $75-80$ & 518 & 27.0 & 439 & 84.7 & 79 & 15.3 & & \\
\hline$>80$ & 283 & 14.8 & 242 & 85.5 & 41 & 14.5 & & \\
\hline Gender & & & & & & & 2.829 & 0.093 \\
\hline Male & 762 & 39.8 & 635 & 83.3 & 127 & 16.7 & & \\
\hline Female & $\mathrm{I}, \mathrm{I} 54$ & 60.2 & 994 & 86.1 & 160 & 13.9 & & \\
\hline Race & & & & & & & 0.319 & 0.572 \\
\hline Han & $\mathrm{I}, 874$ & 97.8 & $\mathrm{I}, 592$ & 85.0 & 282 & 15.0 & & \\
\hline Others & 42 & 2.2 & 37 & 88.1 & 5 & 11.9 & & \\
\hline Residence & & & & & & & 4.549 & $0.033^{\mathrm{a}}$ \\
\hline Urban & 583 & 30.4 & 511 & 87.7 & 72 & 12.3 & & \\
\hline Rural & I,333 & 69.6 & 1,118 & 83.9 & 215 & 16.1 & & \\
\hline Marital status & & & & & & & 0.339 & 0.560 \\
\hline Married & $\mathrm{I}, 520$ & 79.3 & I,296 & 85.3 & 224 & 14.7 & & \\
\hline Others & 396 & 20.7 & 333 & 84.1 & 63 & 15.9 & & \\
\hline Educational level & & & & & & & 12.004 & $0.007^{\mathrm{a}}$ \\
\hline Illiterate & 727 & 37.9 & 623 & 85.7 & 104 & 14.3 & & \\
\hline Primary school & 632 & 33.0 & 539 & 85.3 & 93 & 14.7 & & \\
\hline Middle school & 356 & 18.6 & 285 & 80.1 & 71 & 19.9 & & \\
\hline High school or above & 201 & 10.5 & 182 & 90.5 & 19 & 9.5 & & \\
\hline Family members & & & & & & & 0.018 & 0.893 \\
\hline I & 245 & 12.8 & 209 & 85.3 & 36 & 14.7 & & \\
\hline$>1$ & $|, 67|$ & 87.2 & $\mathrm{I}, 420$ & 85.0 & 251 & 15.0 & & \\
\hline Underprivileged & & & & & & & 0.281 & 0.596 \\
\hline No & $\mathrm{I}, 840$ & 96.0 & I,566 & 85.1 & 274 & 14.9 & & \\
\hline Yes & 76 & 4.0 & 63 & 82.9 & 13 & 17.1 & & \\
\hline Annual household income (yuan) & & & & & & & 7.799 & $0.020^{\mathrm{a}}$ \\
\hline$<48,000$ & 606 & 31.6 & 499 & 82.3 & 107 & 17.7 & & \\
\hline $48,000-68,399$ & 661 & 34.5 & 581 & 87.9 & 80 & 12.1 & & \\
\hline$\geq 68,400$ & 649 & 33.9 & 549 & 84.6 & 100 & 15.4 & & \\
\hline Employment & & & & & & & 4.944 & 0.084 \\
\hline Unemployed & 55 & 2.9 & 43 & 78.2 & 12 & 21.8 & & \\
\hline Employed & 85 & 4.4 & 67 & 78.8 & 18 & 21.2 & & \\
\hline Retired & $\mathrm{I}, 776$ & 92.7 & 1,519 & 85.5 & 257 & 14.5 & & \\
\hline Outpatient medical reimbursement & & & & & & & 11.395 & $0.00 I^{a}$ \\
\hline No & $\mathrm{I}, 348$ & 70.4 & 1,122 & 83.2 & 226 & 16.8 & & \\
\hline Yes & 568 & 29.6 & 507 & 89.3 & 61 & 10.7 & & \\
\hline
\end{tabular}

Note: ${ }^{a} P<0.05$. 
outpatient insurance reimbursement had significantly higher rates of nonadherence. Further comparison in each group was performed, and a statistical significant difference was revealed between the participants in the 35-64, 65-69, and $70-74$ age groups $\left(\chi^{2}=8.320, P=0.004 ; \chi^{2}=9.963, P=0.002\right)$.

Patients aged $<70$ years, those with a middle school degree, and those whose annual household income $<48,000$ yuan had significantly higher nonadherence rates than those aged 70-74 years, with high school degree or above, and whose annual household income was 48,000-68,399 yuan.

Table 2 presents the clinical characteristics of patients. This shows that over half of the patients had hypertensive-related

Table 2 Clinical characteristics of patients with hypertension

\begin{tabular}{|c|c|c|c|c|c|c|c|c|}
\hline \multirow[t]{2}{*}{ Clinical characteristics } & \multicolumn{2}{|c|}{$\begin{array}{l}\text { Total } \\
(n=1,9 \mid 6)\end{array}$} & \multicolumn{2}{|c|}{$\begin{array}{l}\text { Adherence } \\
(n=1,629)\end{array}$} & \multicolumn{2}{|c|}{$\begin{array}{l}\text { Nonadherence } \\
(\mathrm{n}=287)\end{array}$} & \multirow[t]{2}{*}{$\chi^{2}$} & \multirow[t]{2}{*}{$P$-value } \\
\hline & $\mathbf{n}$ & $\%$ & $\mathbf{n}$ & $\%$ & $\mathbf{n}$ & $\%$ & & \\
\hline Self-reported health status & & & & & & & 4.705 & 0.095 \\
\hline (Very) Poor & 352 & 18.4 & 310 & 88.1 & 42 & 11.9 & & \\
\hline Average & 873 & 45.6 & 745 & 85.3 & 128 & 14.7 & & \\
\hline Well & 691 & 36.1 & 574 & 83.1 & 117 & 16.9 & & \\
\hline Self-reported severity of hypertension & & & & & & & 1.624 & 0.654 \\
\hline Asymptomatic & 722 & 37.7 & 619 & 85.7 & 103 & 14.3 & & \\
\hline Mild discomfort & 877 & 45.8 & 736 & 83.9 & $14 \mid$ & 16.1 & & \\
\hline Moderate discomfort & 264 & 13.8 & 228 & 86.4 & 36 & 13.6 & & \\
\hline Extreme discomfort & 53 & 2.8 & 46 & 86.8 & 7 & 13.2 & & \\
\hline Complication & & & & & & & 9.040 & $0.003^{\mathrm{a}}$ \\
\hline No & 697 & 36.4 & 570 & 81.8 & 127 & 18.2 & & \\
\hline Yes & 1,219 & 63.6 & 1,059 & 86.9 & 160 & 13.1 & & \\
\hline Number of comorbidities & & & & & & & 7.423 & $0.024^{a}$ \\
\hline 0 & 331 & 17.3 & 269 & 81.3 & 62 & 18.7 & & \\
\hline I or 2 & 1,089 & 56.8 & 923 & 84.8 & 166 & 15.2 & & \\
\hline$\geq 3$ & 496 & 25.9 & 437 & 88.1 & 59 & 11.9 & & \\
\hline \multicolumn{9}{|l|}{ Comorbidity } \\
\hline Patients with diabetes & 599 & 31.3 & 533 & 89.0 & 66 & 11.0 & 10.734 & $0.00 \mathrm{I}^{\mathrm{a}}$ \\
\hline Patients with heart diseases & 1,018 & 53.1 & 877 & 86.1 & $|4|$ & 13.9 & 2.172 & 0.141 \\
\hline Patients with cerebrovascular diseases & 650 & 33.9 & 562 & 86.5 & 88 & 13.5 & 1.603 & 0.205 \\
\hline Duration (years) & & & & & & & 33.369 & $0.000^{\mathrm{a}}$ \\
\hline $1-4$ & 294 & 15.3 & 221 & 75.2 & 73 & 24.8 & & \\
\hline $5-9$ & 455 & 23.7 & 378 & 83.1 & 77 & 16.9 & & \\
\hline$\geq 10$ & 1,167 & 60.9 & 1,030 & 88.3 & 137 & 11.7 & & \\
\hline Numbers of drugs & & & & & & & 3.536 & 0.171 \\
\hline 1 & 1,364 & 71.2 & 1,150 & 84.3 & 214 & 15.7 & & \\
\hline 2 & 470 & 24.5 & 404 & 86.0 & 66 & 14.0 & & \\
\hline$\geq 3$ & 82 & 4.3 & 75 & 91.5 & 7 & 8.5 & & \\
\hline \multicolumn{9}{|l|}{ Drug classes } \\
\hline Calcium channel blocker & 1,256 & 65.6 & 1,080 & 86.0 & 176 & 14.0 & 2.674 & 0.102 \\
\hline ACE inhibitor & 242 & 12.6 & 203 & 83.9 & 39 & 16.1 & 0.281 & 0.596 \\
\hline ARB & 314 & 16.4 & 276 & 87.9 & 38 & 12.1 & 2.441 & 0.118 \\
\hline$\beta$-Blocker & 339 & 17.7 & 300 & 88.5 & 39 & 11.5 & 3.905 & $0.048^{\mathrm{a}}$ \\
\hline Diuretic & 85 & 4.4 & 73 & 85.9 & 12 & 14.1 & 0.052 & 0.820 \\
\hline Fixed-dose combinations & 148 & 7.7 & 116 & 78.4 & 32 & 21.6 & 5.557 & $0.018^{a}$ \\
\hline Traditional medicines & 83 & 4.3 & 63 & 75.9 & 20 & 24.1 & 5.663 & $0.017^{\mathrm{a}}$ \\
\hline Regular clinical check & & & & & & & 11.964 & $0.00 \mathrm{I}^{\mathrm{a}}$ \\
\hline No & 1,395 & 72.8 & 1,162 & 83.3 & 233 & 16.7 & & \\
\hline Yes & 521 & 27.2 & 467 & 89.6 & 54 & 10.4 & & \\
\hline Regular blood pressure check & & & & & & & 11.939 & $0.00 \mathrm{I}^{\mathrm{a}}$ \\
\hline No & $\mathrm{I}, 208$ & 63.0 & $\mathrm{I}, 00 \mathrm{I}$ & 82.9 & 207 & 17.1 & & \\
\hline Yes & 708 & 37.0 & 628 & 88.7 & 80 & 11.3 & & \\
\hline Blood pressure & & & & & & & 13.693 & $0.000^{\mathrm{a}}$ \\
\hline Uncontrolled & 1,146 & 59.8 & 946 & 82.5 & 200 & 17.5 & & \\
\hline Controlled & 770 & 40.2 & 683 & 88.7 & 87 & 11.3 & & \\
\hline
\end{tabular}


Table 2 (Continued)

\begin{tabular}{|c|c|c|c|c|c|c|c|c|}
\hline \multirow[t]{2}{*}{ Clinical characteristics } & \multicolumn{2}{|c|}{$\begin{array}{l}\text { Total } \\
(n=1,916)\end{array}$} & \multicolumn{2}{|c|}{$\begin{array}{l}\text { Adherence } \\
(n=1,629)\end{array}$} & \multicolumn{2}{|c|}{$\begin{array}{l}\text { Nonadherence } \\
(\mathrm{n}=\mathbf{2 8 7})\end{array}$} & \multirow[t]{2}{*}{$x^{2}$} & \multirow[t]{2}{*}{$\overline{P \text {-value }}$} \\
\hline & $\mathbf{n}$ & $\%$ & $\mathbf{n}$ & $\%$ & $\mathbf{n}$ & $\%$ & & \\
\hline Trust in different doctors & & & & & & & 8.057 & $0.018^{\mathrm{a}}$ \\
\hline Specialist & 1,040 & 54.3 & 897 & 86.3 & 143 & 13.8 & & \\
\hline General practitioner & 529 & 27.6 & 454 & 85.8 & 75 & 14.2 & & \\
\hline Uncertain & 347 & 18.1 & 278 & 80.1 & 69 & 19.9 & & \\
\hline Health service utilizations in the past I year & & & & & & & 0.002 & 0.965 \\
\hline No & $\mathrm{I}, 464$ & 76.4 & $\mathrm{I}, 245$ & 85.0 & 219 & 15.0 & & \\
\hline Yes & 452 & 23.6 & 384 & 85.0 & 68 & 15.0 & & \\
\hline
\end{tabular}

Note: ${ }^{a} p<0.05$.

Abbreviations: ACE, angiotensin-converting enzyme; ARB, angiotensin II receptor blocker.

complications for $>10$ years $(63.6 \%, 60.9 \%)$. Half of the patients had one or two comorbidities (56.8\%). Approximately two-thirds of the patients took one antihypertensive medication (71.2\%). Over half of them were either asymptomatic $(37.7 \%)$ or had experienced just a mild discomfort (45.8\%). Furthermore, only one-third of the patients checked their blood pressure regularly $(37.0 \%)$, and only a few of them checked their health regularly $(27.2 \%)$. More than half of the patients were not able to achieve a normal blood pressure (59.8\%), and a few of them were trustful of the general practitioners (27.6\%). Patients without hypertension-related complications, those with shorter duration of hypertension, those who had not checked their health or blood pressure regularly, those without diabetes, those taking fixed-dose combination medications, those taking traditional medications, and those with uncontrolled blood pressure were more likely nonadherent to their antihypertensive medication regimen. Moreover, further comparison found that patients with no comorbidities had significantly higher nonadherence rates than those with over three comorbidities $\left(\chi^{2}=7.427\right.$, $P=0.006$ ). Similarly, patients who were uncertain to trust doctors had significantly higher nonadherence rates than those who trust the specialists $\left(\chi^{2}=7.562, P=0.006\right)$.

\section{Results of the principal component analysis of factors}

This study examined the correlation between all variables (data are shown in the Supplementary material). The results showed strong correlations in many variables besides race. In addition, the questions about comorbidities and drug classes were presented in multiple choice questions in the questionnaire, which could not be used for the principal component analysis. Then we conducted the component analysis with factors except race, comorbidities, and drug classes. The results of the principal component analysis of the factors are shown in Table 3. This study performed the Kaiser-MeyerOlkin (KMO) and Bartlett's test of sphericity and found a potential correlation between the factors in this study; thus, it was fit to conduct a factor analysis (KMO value is 0.650 , Bartlett's test $P$-value $<0.001)$. This study extracted nine common factors, that is, severity of disease, family, community management, individual factor, social factor, health status, gender, treatment, and economic status, and the cumulative variance contribution rates reached $63.625 \%$. The initial eigenvalues for all nine factors were $2.475,2.334,1.697,1.392$, $1.22,1.193,1.059,1.017$, and 0.974 ; all of them were $>0.5$. The first common factor represents the following five variables: complication, number of comorbidities, outpatient medical reimbursement, duration, and self-reported severity of hypertension. The second common factor could explain the following three variables: marital status, family members, and annual household income. Similarly, the third common factor represents blood pressure, regular clinical check, and regular blood pressure check. Moreover, the fourth common factor indicates the patient's residence and age. The fifth common factor comprises patient's educational level and employment. The sixth common factor reflects only self-reported health status. Gender is mainly explained by the seventh factor. The eighth common factor reflected the numbers of drugs, health service utilizations in past year, and trust in different doctors. The last common factor explains the underprivileged solely.

\section{Factors related to nonadherence in the logistic regression analysis}

Table 4 presented the common factors that were associated with medication nonadherence; this study found that severity of disease, community management, and patients with diabetes had a statistically significant negative association with nonadherence $(P<0.05)$. Those who had no complications, had no comorbidities, had not availed the outpatient medical 
Table 3 Coefficient of factor loading and total variance explained in principal component analysis

\begin{tabular}{|c|c|c|c|c|c|c|c|c|c|}
\hline Variables & FI & $\mathbf{F 2}$ & F3 & F4 & F5 & F6 & F7 & F8 & F9 \\
\hline Complication & 0.760 & -0.122 & -0.034 & 0.016 & -0.116 & -0.169 & 0.102 & 0.298 & -0.041 \\
\hline Number of comorbidities & 0.613 & -0.186 & -0.070 & 0.120 & 0.014 & 0.152 & 0.102 & 0.318 & -0.178 \\
\hline Outpatient medical reimbursement & 0.604 & 0.105 & 0.015 & -0.030 & -0.136 & -0.422 & 0.154 & 0.212 & -0.004 \\
\hline Duration & 0.447 & -0.080 & 0.012 & -0.326 & 0.122 & 0.080 & 0.389 & -0.100 & 0.112 \\
\hline Self-reported severity of hypertension & 0.437 & -0.247 & -0.158 & 0.193 & 0.002 & 0.325 & -0.235 & 0.013 & -0.26 \\
\hline Marital status & 0.149 & 0.785 & -0.198 & 0.186 & 0.168 & 0.122 & -0.042 & -0.016 & 0.073 \\
\hline Family members & 0.194 & 0.734 & -0.223 & 0.179 & 0.185 & 0.241 & 0.013 & -0.002 & 0.152 \\
\hline Annual household income & 0.279 & 0.670 & -0.014 & -0.152 & 0.230 & 0.143 & 0.023 & 0.016 & 0.040 \\
\hline Blood pressure & 0.063 & 0.098 & 0.796 & 0.165 & 0.144 & 0.026 & -0.048 & 0.123 & 0.017 \\
\hline Regular clinical check & 0.074 & 0.070 & 0.716 & 0.262 & 0.118 & 0.011 & -0.019 & -0.013 & 0.105 \\
\hline Regular blood pressure check & 0.210 & 0.093 & $0.56 I$ & 0.002 & -0.011 & 0.036 & -0.130 & -0.036 & -0.077 \\
\hline Residence & -0.117 & -0.096 & -0.251 & 0.566 & 0.214 & -0.379 & -0.031 & 0.269 & 0.121 \\
\hline Age & 0.237 & -0.263 & 0.015 & -0.536 & 0.223 & 0.017 & -0.448 & 0.085 & 0.203 \\
\hline Educational level & 0.015 & 0.473 & 0.170 & -0.180 & -0.547 & -0.117 & -0.019 & -0.045 & -0.285 \\
\hline Employment & 0.184 & -0.019 & 0.016 & -0.388 & 0.483 & -0.295 & -0.122 & -0.112 & 0.144 \\
\hline Self-reported health status & -0.323 & 0.190 & 0.083 & -0.041 & 0.080 & -0.476 & 0.338 & 0.094 & 0.138 \\
\hline Gender & 0.070 & -0.448 & 0.078 & 0.215 & 0.315 & 0.307 & 0.507 & -0.220 & 0.015 \\
\hline Numbers of drugs & 0.339 & 0.038 & 0.003 & -0.098 & -0.345 & -0.019 & 0.272 & -0.427 & 0.262 \\
\hline Health service utilizations in the past I year & 0.334 & -0.066 & -0.003 & 0.348 & -0.166 & -0.110 & -0.270 & -0.395 & 0.214 \\
\hline Trust in different doctors & -0.364 & 0.130 & 0.101 & -0.277 & -0.039 & 0.310 & 0.219 & 0.382 & -0.069 \\
\hline Underprivileged & -0.050 & -0.131 & 0.022 & 0.032 & -0.376 & 0.286 & -0.047 & 0.345 & 0.720 \\
\hline Initial eigenvalues & 2.475 & 2.334 & 1.697 & 1.392 & 1.220 & 1.193 & 1.059 & 1.017 & 0.974 \\
\hline Cumulative \% & 11.786 & 22.903 & 30.985 & 37.615 & 43.423 & 49.102 & 54.143 & 58.986 & 63.625 \\
\hline
\end{tabular}

Notes: Bold entries reflect the information of specific original variables that each of factors (FI-F9) included. Some original variables' information also marked as bold entries, because they have a higher value in the corresponding factors, although these original variables were included in other factors at last based on highest value. FI reflects complication, number of comorbidities, outpatient medical reimbursement, duration, self-reported severity of hypertension, named severity of disease factor; F2 reflects marital status, family members, annual household income, named family factor; F3 reflects blood pressure, regular clinical check, regular blood pressure check, named community management factor; F4 reflects residence and age, named individual factor; F5 reflects educational level and employment, named social factor; F6 reflects selfreported health status, named health status factor; F7 reflects gender, named gender factor; F8 reflects number of drugs, health service utilization in the past I year,and trust in different doctors, named treatment factor; F9 reflects underprivileged, named economic status factor.

Abbreviation: $F$, factor.

reimbursement, had a shorter duration of hypertension, and had slight symptoms of hypertension were more likely nonadherent, whose nonadherence rate was 0.654 times lower than that of patients who had complications, had comorbidities, had availed the outpatient medical reimbursement, had a longer duration of hypertension, and had serious symptoms of hypertension. Similarly, patients with uncontrolled blood pressure and those without regular health or blood pressure check were more likely nonadherent, whose nonadherence rate was 0.731 times lower than that of patients with controlled blood pressure and those with regular health or blood pressure check. The nonadherence rate of patients with diabetes was 0.656 times lower than that of patients without diabetes. Taking traditional medicines was positively associated with nonadherence. This study found that severity of disease was the main factor associated with medication nonadherence.

Table 4 Common factors associated with medication nonadherence using a binary logistic regression analysis

\begin{tabular}{|c|c|c|c|c|}
\hline Associated factors & Crude OR $(95 \% \mathrm{Cl})$ & $P$-value & Adjusted $\mathrm{OR}^{\mathrm{b}}(95 \% \mathrm{Cl})$ & $P$-value \\
\hline Patients with diabetes & $0.614(0.458,0.824)$ & $0.00 \mathrm{I}^{\mathrm{a}}$ & $0.656(0.479,0.898)$ & $0.008^{a}$ \\
\hline$\beta$-Blocker & $0.697(0.486,0.999)$ & $0.049^{a}$ & $0.979(0.609,1.573)$ & 0.929 \\
\hline Fixed-dose combinations & $1.637(1.083,2.474)$ & $0.019^{\mathrm{a}}$ & $1.638(0.955,2.808)$ & 0.073 \\
\hline Traditional medicines & $1.862(1.108,3.130)$ & $0.019^{a}$ & $2.096(1.097,4.005)$ & $0.025^{\mathrm{a}}$ \\
\hline Severity of disease (FI) & $0.702(0.617,0.799)$ & $0.000^{\mathrm{a}}$ & $0.654(0.538,0.795)$ & $0.000^{\mathrm{a}}$ \\
\hline Family (F2) & $1.016(0.896,1.153)$ & 0.802 & $1.013(0.886,1.157)$ & 0.853 \\
\hline Community management (F3) & $0.743(0.649,0.850)$ & $0.000^{\mathrm{a}}$ & $0.731(0.635,0.842)$ & $0.000^{\mathrm{a}}$ \\
\hline Individual factor (F4) & I.I0I $(0.972,1.248)$ & 0.131 & $1.090(0.956,1.242)$ & 0.197 \\
\hline Social factor (F5) & $0.896(0.793,1.013)$ & 0.078 & $0.917(0.798,1.054)$ & 0.223 \\
\hline Health status (F6) & $0.989(0.872,1.122)$ & 0.866 & $0.990(0.868,1.130)$ & 0.883 \\
\hline Gender (F7) & $0.897(0.791,1.017)$ & 0.088 & $0.889(0.776,1.019)$ & 0.090 \\
\hline Treatment (F8) & $1.060(0.935,1.202)$ & 0.360 & $1.074(0.917,1.258)$ & 0.376 \\
\hline Economic factor (F9) & $0.96 \mathrm{I}(0.845, \mathrm{I} .093)$ & 0.545 & $0.930(0.813,1.065)$ & 0.294 \\
\hline
\end{tabular}

Notes: ${ }^{a}<0.05$. ${ }^{b}$ The regression model was adjusted for residence, patients with heart diseases, patients with cerebrovascular diseases, calcium channel blocker, ACE inhibitor, ARB, and diuretic.

Abbreviations: OR, odds ratio; $A C E$, angiotensin-converting enzyme; ARB, angiotensin II receptor blocker; F, factor. 


\section{Discussion}

Medication adherence is a key factor in achieving blood pressure control in patients with hypertension. Hence, finding the key factor affecting adherence to antihypertensive medications among community-managed patients with hypertension is important in improving the medication adherence. Prior studies have found that community management is one of the main factors that influenced the effects of treatment and blood pressure control in patients with hypertension. This study extracted nine common factors based on principal component analysis. Further logistic regression analysis found severity of disease factor, community-managed factor, taking traditional medications, and patients with diabetes as factors associated with antihypertensive medication nonadherence. We found that community management could increase the medication adherence in hypertensive patients; hence, we should insist community management in hypertensive patients and constantly improve management measures, improving patients' medication adherence and health outcomes.

Similar to prior studies, this study found that severity of disease factor is one of the factors of adherence in our results $(\mathrm{OR}=0.654, P<0.001)$. Hypertension is largely asymptomatic. Prior studies reported that patients with more chronic diseases, those having hypertension-related complications, or those with a longer duration of hypertension more likely received a regular care, understood the importance of adherence, and developed good habits of taking antihypertensive medications; therefore, their medication adherence improved. ${ }^{30,46}$ The results of this study were consistent with that of the previous studies. In China, the outpatient medical reimbursement policy was developed for chronic patients with complications; thus, utilization of this reimbursement policy is reflective of the severity of patients' diseases. Patients who availed the policy have the privilege to receive a $60 \%-80 \%$ reimbursement of the medication cost combined with a coinsurance at a limit of 1,500-2,000 yuan each year. This study used principal component analysis and found that the outpatient reimbursement policy was developed based on the severity of patients' diseases; thus, this policy can relieve patients' financial burden to some extent and improve patients' medication adherence. Our results are consistent with the findings of other studies ${ }^{47}$ Meanwhile, these results would warn us whether patients with mild hypertension should be covered by the outpatient reimbursement policy or not; the feasibility could be explored in further studies.

This study revealed that community management increased patients' medication adherence. Shaik et al found that patients who were under poor community management were nonadherent to antihypertensive medication regimen. ${ }^{30}$ We also found that patients who do not have regular clinical and blood pressure checks and those who were not able to control their blood pressure were more likely nonadherent to their medication regimen. Thus, general practitioners should improve the standardized management and health education for patients with hypertension. In this study, around one-third of the hypertension patients with the comorbidity of diabetes were managed in the community due to hypertension and diabetes in 2009. The method used by general practitioners in managing patients with diabetes is the same as that used in patients with hypertension. One study conducted a survey on individuals with hypertension in Medicaid and reported that the comorbidities of diabetes were associated with decreased nonadherence to antihypertensive medications $(\mathrm{OR}=0.76, P<0.0001) .{ }^{27} \mathrm{We}$ also found that patients with diabetes were adherent to their antihypertensive medications ( $\mathrm{OR}=0.656, P<0.05$ ). There maybe two reasons for this: if patients have both hypertension and diabetes, they will be dual managed by primary health-care providers in China, that is, these patients will recieve hypertension related community management and also diabetes related community management. The community management efforts for them are reinforced, potentially there will be improvements on medication adherence.

To our surprise, in this literature, only $27.6 \%$ of the patients trusted their general practitioners, and $54.3 \%$ of them placed more trust in their specialists. In 2016, a community family physician model was put into force in China, which formed a service team composed of clinicians, general practitioners or village doctors, community nurses, and public health doctors. Patients with hypertension, patients with diabetes, elderly, and other target population were covered as a matter of priority. As the community family physician model was carried out, acceptance, trust, and compliance to primary health care institutions were improved in patients with hypertension living in Xinjiang, which is a good advantage for primary health care providers to manage and educate patients with hypertension. ${ }^{48}$

Another important finding was that patients who took traditional medications were considered nonadherent. This result was consistent with the findings of other studies. ${ }^{49-51}$ About $4.3 \%$ of the patients took traditional medications to control their blood pressure. Accordingly, $91.6 \%$ of the patients used Apocynum venetum. A. venetum is not included in the list of recommended antihypertensive medications. We found that some patients took $A$. venetum either as a tea or as a preparation to replace other antihypertensive medications. This made the 
patients' medication regimen complicated as the $A$. venetum had potentially harmful effects. This may be one of the factors contributing to the poor medication adherence among patients with hypertension who take traditional medications.

This study had several limitations. We could not perform the study to compare the adherence of patients with hypertension managed by community or not, because control group without community management was difficulty to be found in China. We could conduct further study to compare adherence of those with hypertension with short-time community management and those with long-time community management so as to explore the relationship between the adherence and community management through cohort study.

\section{Conclusion}

The data from this study showed that patients with less severity of diseases, those having poor community management, those without diabetes, and those who took traditional medications were nonadherent to their antihypertensive medication regimen. Community management plays an important role in improving the patients' medication-taking behavior. Unlike the socioeconomic and disease determinants that can be difficult to change, regular provision of medication instructions and improved community management services at the community level can potentially reduce nonadherence. Managing patients with mild hypertension is the main focus of community health care providers to strengthen their standardized management and prevent the occurrence of complications and other adverse outcomes. Professional quality training of general practitioners should be strengthened to improve their patients' trust. This study evaluated the factors affecting medication adherence among patients with hypertension living in Xinjiang, with some references to areas with poor health resources and underdeveloped economic conditions.

\section{Acknowledgments}

The authors would like to thank the Department of Public Health, Shihezi University School of Medicine, for providing assistance and the National Natural Science Foundation of China for the funding (project identification code: 71363047). Yuji Zhang and Xiaoju Li are co-first authors for this paper.

\section{Author contributions}

Yuji Zhang performed data analysis and wrote the manuscript. Mingxia Jing designed the study and organized the survey and led the writing of the paper; Yuji Zhang and Xiaoju Li was jointly involved in the manuscript discussion and revision; Lu Mao, Mei Zhang, Ke Li, Yinxia Zheng,
Wangfei Cui, Hongpo Yin, and Yanli He provided the statistics consultation and revised the paper. Yuji Zhang and Xiaoju Li wrote the paper. All authors contributed toward data analysis, drafting and revising the paper and agree to be accountable for all aspects of the work.

\section{Disclosure}

The authors report no conflicts of interest in this work.

\section{References}

1. Aronow WS, Fleg JL, Pepine CJ, et al. ACCF/AHA 2011 Expert consensus document on hypertension in the elderly. J Am Soc Hypertens. 2011;5(4):259-352.

2. Carslaw H, Cosh A. Hypertension. InnovAiT. 2017;10(5):276-281.

3. WHO.int [homepage on the Internet]. Global status report on noncommunicable diseases 2014; 2014:298. Available from: www. who.int $/ \mathrm{nmh} / \mathrm{pub}$ lications/ncd-status-report-2014/en/. Accessed November 10, 2017.

4. Lewington S, Lacey B, Clarke R, et al. The burden of hypertension and associated risk for cardiovascular mortality in China. JAMA. 2016; 176(4):524-532.

5. Chobanian AV, Bakris GL, Black HR, et al. Seventh report of the joint national committee on prevention, detection, evaluation, and treatment of high blood pressure. Hypertension. 2003;42(6):1206-1252.

6. Al-Ramahi R. Adherence to medications and associated factors: a crosssectional study among Palestinian hypertensive patients. J Epidemiol Glob Health. 2015;5(2):125-132.

7. Morrison VL, Holmes EAF, Parveen S, et al. Predictors of self-reported adherence to antihypertensive medicines: a multinational, crosssectional survey. Value Health. 2015;18(2):206-216.

8. Ma C. A cross-sectional survey of medication adherence and associated factors for rural patients with hypertension. Appl Nurs Res. 2016; 31:94-99.

9. Zhai J. Analysis of the influencing factors of drug compliance in patients with hypertension and hyperlipidemia treatment. China J Pharm Econ. 2015;(3):135-136.

10. Zhong W. Investigative analysis of the influence factors of compliance of patients with antihypertensive therapy. Mod Prev Med. 2011;38(18): 3826-3827.

11. Shaw R, Bosworth HB. Baseline medication adherence and blood pressure in a 24-month longitudinal hypertension study. J Clin Nurs. 2012;21(9-10):1401-1406.

12. Fikri-Benbrahim N, Faus MJ, Martínez-MartínezF, Sabater-Hernández D. Impact of a community pharmacists' hypertension-care service on medication adherence. Res Social Adm Pharm. 2013;9(6):797-805.

13. Lee JK, Grace KA, Taylor AJ. Effect of a pharmacy care program on medication adherence and persistence, blood pressure, and lowdensity lipoprotein cholesterol: a randomized controlled trial. JAMA. 2006;296(21):2563.

14. Machado M, Bajcar J, Guzzo GC, et al. Sensitivity of patient outcomes to pharmacist interventions - part II: systematic review and metaanalysis in hypertension management. Ann Pharmacother. 2007;41(10): 1569-1582.

15. Morgado MP, Morgado SR, Mendes LC, Pereira LJ, Castelobranco M. Pharmacist interventions to enhance blood pressure control and adherence to antihypertensive therapy: review and meta-analysis. Am J Health Syst Pharm. 2011;68(3):241-253.

16. Li Y, Wang JL, Zhang XC, et al. Effectiveness of adherence to standardized hypertension management by primary health care workers in China: a cross-sectional survey 3 years after the healthcare reform. Binmed Environ Sci. 2016;29(12):915-921.

17. Maimaris W, Paty J, Perel P, et al. The influence of health systems on hypertension awareness, treatment, and control: a systematic literature review. PLoS Med. 2013;10(7):e1001490. 
18. Bandi P, Goldmann E, Parikh NS, Farsi P, Bodenalbala B. Age-related differences in antihypertensive medication adherence in Hispanics: a cross-sectional community-based survey in New York city, 2011-2012. Prev Chronic Dis. 2017;14(7):E57.

19. Bishopric NH, Nguyen T-P-L, Schuiling-Veninga CCM, et al. Adherence to hypertension medication: quantitative and qualitative investigations in a rural northern Vietnamese community. PLoS One. 2017; 12(2):e0171203.

20. Wang W, Lau Y, Loo A, Chow A, Thompson DR. Medication adherence and its associated factors among Chinese community-dwelling older adults with hypertension. Heart Lung. 2014;43(4):278-283.

21. Meng J, Ou L, Xu L, Shen G, Zhu Q, Qian F. Logistic regression analysis of medication adherence and influencing factors among hypertensive patients in community. Chinese Prim Health Care. 2014;28(8): 31-33.

22. Qiao X, Zhou J, Yang X, et al. Predicting medication adherence in community-dwelling older patients with chronic diseases. Chinese $J$ Gerontol. 2017;37(13).

23. Wang J, Lin S, Yang Y, et al. Medication adherence and its influencing factors of community multimorbidity patients. Chinese Gen Pract. 2017;20(23).

24. Yan N. Pine management of community patients with hypertension medication adherence. Med Inform. 2014;(11):216-217.

25. Zhang Y, Fang Y, Li G, Duan G. Medication adherence among middleaged and elderly community residents with hypertension and its related factors. J Nurs Sci. 2010;25(3):13-15.

26. Baggarly SA, Kemp RJ, Wang X, Magoun AD. Factors associated with medication adherence and persistence of treatment for hypertension in a Medicaid population. Res Social Adm Pharm. 2014;10(6):e99-e112.

27. Bailey JE, Hajjar M, Shoib B, Tang J, Ray MM, Wan JY. Risk factors associated with antihypertensive medication nonadherence in a statewide medicaid population. Am J Med Sci. 2014;348(5):410-415.

28. Kang CD, Tsang PPM, Li WTL, et al. Determinants of medication adherence and blood pressure control among hypertensive patients in Hong Kong: a cross-sectional study. Int J Cardiol. 2015;182:250-257.

29. Karakurt P, Kasikci M. Factors affecting medication adherence in patients with hypertension. J Vasc Nurs. 2012;30(4):118-126.

30. Shaik SA, Alsuwailem A, Alhargan A, et al. Medications adherence level and its associated factors among hypertensive patients at a major referral hospital, in Riyadh, KSA. Asian J Med Sci. 2016;7(4):24-30.

31. Teshome DF, Bantie Bekele K, Habitu Y, Addis Gelagay A. Medication adherence and its associated factors among hypertensive patients attending the Debre Tabor General Hospital, northwest Ethiopia. Integr Blood Press Control. 2017;10:1-7.

32. The Xinjiang Production and Construction Corps [homepage on the Internet]. Available from: http:/www.xjbt.gov.cn/c/2016-1115/2943499.shtml. Accessed November 2016.

33. Statistic Bureau of Xinjiang Uygur Autonomous Region [homepage on the Internet]. Available from: http://www.xjtj.gov.cn/sjcx/ tjnj_3415/2016xjtjnj/gmjjhs/201707/t20170714_539428.html. Accessed March 2017.

34. Guan Y, Liu L, Zhe W, et al. Analysis on hypertension prevalence among residents in Xinjiang monitoring stations, 2010. Chinese $J$ Health Educ. 2014;30(11):971-975.
35. Deng L. Analysis and nursing measures of drug compliance in community hypertension patients. J Front Med. 2017;7(15):279-280.

36. Lu Y, Zhao J, Lin J, Pan Y, Zhu Y. Association of medication adherence and self-efficacy of hypertensive patients in Huangpu District of Shanghai City. Chinese J Health Educ. 2017;33(3):228-231.

37. Wu L, Li Y. Correlations between society support, treatment compliance and blood pressure control among hypertensive patients. J Clin Med. 2017;4(36):7099-7100.

38. Zhang X, Lu X. Analysis of the influencing factors of drug compliance in patients with hypertension and hyperlipidemia treatment. China Healthc Front. 2009;04(3):107-108.

39. Zhao J, Fan F, Yao L. Investigation of compliance with drugs in patients with chronic diseases and its influential factors. Pharm Care Res. 2011;(02):130-133.

40. Zheng X, Pu C. Survey analysis on medication compliance influence factors in 420 cases of patients with high blood pressure. J Mod Clin Med. 2012;20(1):77-78.

41. He L. Correlations between society support, treatment compliance and blood pressure control among hypertensive patients. China Health Care Nutr. 2017;27(18).

42. Oliva RV, Bakris GL. Management of hypertension in the elderly population. J Gerontol. 2012;67(12):1343-1351.

43. China Hypertension Prevention Guidelines Revision Committee. 2010 Chinese guidelines for the management of hypertension. Chinese J Cardiol. 2011;39(7):701-708.

44. Ye X, Lin F, Chen W. Study on influential factors of compliance to antihypertensive medications. Mod Prev Med. 2007;34(3):494-496.

45. Zhang R. The Impact of Rural Health Policy Elements on Health Seeking Behaviors and Healthcare Expenditure among Rural Patients with Hypertension - The Empirical Research of Eight Counties in Shandong Province Based on Hierarchical Linear Model (HLM) [doctoral thesis]. Shandong, China: Shandong Univercity; 2012.

46. Hunt JS, Siemienczuk J, Touchette D, Payne N. Impact of educational mailing on the blood pressure of primary care patients with mild hypertension. J Gen Intern Med. 2004;19(9):925-930.

47. Zhang Y, Lave JR, Donohue JM, Fischer MA, Chernew ME, Newhouse JP. The impact of Medicare Part D on medication adherence among older adults enrolled in Medicare-advantage products. Med Care. 2010;48(5):409-417.

48. Department of System Reform of National Health and Family Planning Commission [homepage on the Internet]. Available from: http:// www.nhfpc.gov.cn/tigs/s3577/201606/e3e7d2670a8b4163b1fe8e409c7887af.shtml. Accessed June 2016.

49. Boima V, Ademola AD, Odusola AO, et al. Factors associated with medication nonadherence among hypertensives in Ghana and Nigeria. Int J Hypertens. 2015;2015:1-8.

50. Liwa A, Roediger R, Jaka H, et al. Herbal and alternative medicine use in Tanzanian adults admitted with hypertension-related diseases: a mixed-methods study. Int J Hypertens. 2017;2017(3):5692572.

51. Osamor PE, Owumi BE. Factors associated with treatment compliance in hypertension in Southwest Nigeria. J Health Popul Nutr. 2011; 29(6):619
Patient Preference and Adherence

\section{Publish your work in this journal}

Patient Preference and Adherence is an international, peer-reviewed, open access journal that focuses on the growing importance of patient preference and adherence throughout the therapeutic continuum. Patient satisfaction, acceptability, quality of life, compliance, persistence and their role in developing new therapeutic modalities and compounds to optimize

\section{Dovepress}

clinical outcomes for existing disease states are major areas of interest for the journal. This journal has been accepted for indexing on PubMed Central. The manuscript management system is completely online and includes a very quick and fair peer-review system, which is all easy to use. Visit http://www. dovepress.com/testimonials.php to read real quotes from published authors. 